Poor technological infrastructure, low bandwidth availability, and language remain important barriers to online access. There is a growing risk of overlapping activity in online and distance learning due to the proliferation of players in the market, and several e-university ventures have collapsed after the initial funding period ended.

Until now, transnational higher education in French-speaking Africa has developed in relative isolation from the other language communities on the continent. One site where the anglophone and francophone worlds meet is the African Virtual University (AVU). In March 2004, the AUF formed a partnership with the AVU to collaborate in the development of course content in French. The AVU's recent partnership with the agency might be viewed as an attempt to bridge the existing divide and promote institutional collaboration between the two language communities. The prospects of cross-fertilization (rather than ongoing separate development by language) remain unclear.

\section{ISSUES AND IMPLICATIONS}

There is currently a paucity of information on foreign educational activity in French-speaking Africa. An overview of crossborder developments suggests that transnational activity based on the capacity-building model can develop on a substantial scale, but the prospects for long-term sustainability remain less clear. Large-scale developments are almost exclusively concentrated in the more developed countries of the subregion. This trend is likely to continue as incoming providers attempt to achieve a more refined balance between developmental/commercial objectives. Mauritius, Tunisia, and Senegal offer good examples of how national governments can put in place a range of structures and incentives to bring foreign educational provision into the mainstream.

How might countries in francophone Africa maximize the developmental benefits and minimize the potential risks of transnational higher education?

It is indisputable that over the past decade transnational activity has expanded significantly in French-speaking Africa, foreign ventures have become more ambitious and the type of providers has become increasingly diverse. As cross-border activity becomes increasingly widespread across the subregion, the question begs to be raised: how might countries in francophone Africa maximize the developmental benefits and minimize the potential risks of transnational higher education? Future innovation may emphasize the value of improved data collection, tighter quality assurance, mission coordination, and impact assessment. Regional bodies such as the AUF, AVU, and the African and Malgache Higher Education Council might assume an increasingly central role in overseeing transnational developments, particularly as incoming providers move toward a more economically driven approach. Host countries might also wish to consider developing appropriate quality assurance mechanisms for imported educational activity and imposing development-based conditions on foreign establishment. Until questions are raised over the extent to which foreign provision seriously addresses the development agenda of the host country, the added-value potential of transnational higher education to the subregion will remain largely unknown.

For further details, please refer to the two-part report "Higher Education Crossing Border in Francophone Africa: Opportunities, Challenges and Implications" at www.obhe.ac.uk..

\section{Cost Sharing in Higher Education Financing: Economic Perils in Developing Countries}

\section{Carlo Salerno}

Carlo Salerno is a senior research associate at the Centre for Higher Education Policy Studies (CHEPS), University of Twente. Address: CHEPS, University of Twente, PO Box 217, 7500 AE Enschede, Netherlands. Tel: +31.53.489.2031. E-mail: c.s.salerno@bbt.utwente.nl.

Cost sharing, shifting part of the burden for financing higher education away from the state and onto students and families, is a phenomenon that has taken on global proportions. Nowhere, though, has it received greater endorsement than in the developing world and particularly in sub-Saharan Africa. A shortage of public funding, rapidly expanding enrollments, and strong endorsement from international aid agencies like the World Bank have all worked in concert to push cost sharing as the way for such nations to strengthen their fragile higher education sectors and spur economic growth.

The practice makes for sound economic policy, particularly on equity grounds. Investment in higher education yields significant private returns; and from an equity standpoint, whoever benefits ought to pay. Since both individuals and society reap the rewards from education, an equitable financing scheme implies sharing the costs. The potential gains from cost sharing are readily apparent in the success of its most ardent fans: Anglo-Saxon countries. Indeed, one of the major strengths behind the American, British, and Australian systems is their universities' ability to exploit this supplemental 
income and leverage their reputations through the presence of high-quality faculty, talented students, and state-of-the-art facilities.

Yet what is good for the goose is not necessarily good for the gander. The introduction of cost-sharing mechanisms in developing countries has certainly generated much-needed revenues for perennially underfunded systems. At the same time, the unintended consequences stemming from the way it has been adapted to fit these countries' unique economic circumstances raise serious concerns about the appropriateness of cost sharing as a long-term financing strategy.

\section{Where Do the Problems Lie?}

The term cost sharing subsumes many different practices and the debate surrounding it is as much political as it is economic. There are three fundamental differences between the phenomenon and its application in developed and developing countries. The first is its distribution across the student population. In places like the United States, all students at both public and private institutions receive some type of subsidy and pay some level of fees, whereas places like Ethiopia or Uganda tend to fully subsidize a small number of academically talented students and charge all other students the full cost. The second involves the funding recipients. Tuition revenues from cost sharing in developed countries have largely benefited public institutions; however, in developing countries publics garner some of the new private financing, but a substantial portion is channeled into the development of a parallel private higher education sector. The third distinction deals with the underlying infrastructure. Countries like the United States, the United Kingdom, and Australia have created schemes to make education nearly costless at the point of use and repayment manageable over time and under differing economic circumstances. Developing countries have introduced tuition but, lacking the relevant infrastructure, have done so without a functioning loan or grants scheme.

Without the necessary support infrastructure, this particular form of cost sharing is also hindering developing nations' overall economic growth.

The first problem is that instead of promoting equity, cost sharing in developing countries discourages it. Taxpayers fund public services they can then use, but only a very small fraction of the public actually enjoys the benefit. And since that public subsidy is based on merit, those who do receive the subsidy are least likely to need it: the wealthy children who have attended the best primary and secondary schools. For the overwhelming majority of the college-going population, cost sharing effectively becomes "cost shouldering."

Second, without the necessary support infrastructure, this particular form of cost sharing is also hindering developing nations' overall economic growth. Annual tuition at public institutions may only run into the hundreds of dollars (and at privates in the low thousands); but when per capita GDP is less than \$I,००0, the up-front investment is remarkably high. Driven by the belief in what it can provide, cost sharing forces families to invest an unreasonably large percentage of their available income into education (particularly a small number of professional fields), which drives down consumer demand for goods in other areas of the economy. Rapid annual growth in the number of graduates may be lauded by many, but the high unemployment level among such individuals provides evidence that this mode of financing may in fact be responsible for depressing national growth by oversupplying labor markets while simultaneously depressing consumer demand.

The third and perhaps most interesting problem is that the additional funding is being channeled mainly to newly established private providers. Often referred to as "garage colleges," most are small for-profits that open and close with alarming frequency and generally only offer professional programs in business, education, or computer science. From an economic standpoint, it is questionable whether such a large percentage of tuition funding ought to be allocated toward the provision of a narrow set of programmatic offerings at institutions that have considerable incentive to overcharge students and shirk on quality. Moreover, such a strategy does little to enhance access by encouraging a more even geographic distribution of higher education providers. For-profit privates' most lucrative markets are the same populous areas in which the small numbers of public institutions operate.

\section{Is There a SOLution?}

Unfortunately, identifying a more preferable alternative financing scheme is difficult. One obvious solution would be to design the current system of subsidies on the basis of need rather than merit. The difficulty, of course, is how to calculate need in such a situation. Another solution would be to more evenly distribute public subsidies or create a rudimentary loan scheme using nontraditional cost-recovery mechanisms (e.g., the introduction of promissory notes and tax deductions). Such a system will invariably lose money, but this must be weighed against the benefits it provides by increasing participation and freeing up current income that can be spent on strengthening other consumer markets.

Managing the relationship between cost sharing and private expansion is tricky. An effective quality assurance mechanism can help ensure that tuition fees going to private providers are invested in education activities rather than investors' pockets, but it cannot encourage a for-profit-dominated private sector to provide loss-making yet economically crucial nonprofessional programs needed for meeting the national labor market's needs. If the strategy is to support a private system, then more must be done to discover financial incentives that will encourage privates to offer a broader curriculum more capable of meeting the countries' labor-market needs. 
Private financing of higher education is clearly crucial to maintaining an efficient, quality-driven system, but it is not a panacea for the problems currently facing developing countries. The push for a more balanced mix of public and private funding is necessary, but the way it has been so whole-heartedly and rapidly embraced is disconcerting without further research on the economic consequences that cost sharing will have on developing countries in the long run.

\section{The New Landscape of International Student Mobility}

\section{Hey-Kyung Кон Chin}

Hey-Kyung Koh Chin is senior program officer of research and evaluation, at the Institute of International Education in New York City. She is also the editor of the Open Doors Report on International Educational Exchange. Address: Institute of International Education, 809 United Nations Plaza, New York, New York 10036. E-mail: HKOH@iie.org.

S ome patterns and shifts emerge in comparing data for

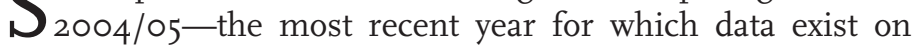
international students in US higher education from the Open Doors Report on International Educational Exchange-with the previous year. The regions of origin of international students remained virtually unchanged in 2004/05. As has been the case for many decades, the largest proportion of international students came from Asia (57 percent), up I percent from 2003/04. Enrollments from Europe (I3 percent) and Latin America (I2 percent) remained the same, while enrollments from Africa ( 6 percent) declined I percent, and those from North America (5 percent) and the Middle East ( 6 percent) remained unchanged. India was the leading place of origin of international students for the fourth year in a row, with 80,466 students in the United States (I4 percent of the total). But after several years of double-digit growth, the increase from $2003 / 04$ to $2004 / 05$ was only I percent. Five-year enrollment trends for the other three leading sending countries showed varied rates of growth: enrollments from China, the secondlargest sender, increased until 2002/03, declined in 2003/04, then increased slightly in 2004/05; enrollments from Japan increased until 2001/02, declined slightly in 2002/03, declined steeply in 2003/04, and increased again 2004/05; and enrollments from Korea experienced a steady increase throughout.

In the United States the distribution of international students by state has not changed much over time. The five leading host states in 2004/05 were California, New York, Texas, Massachusetts, and Florida. New York City was once again the largest metropolitan area hosting international students, followed by Los Angeles, Boston, Washington DC, and Chicago. International students tended to be heavily concentrated within the United States: the leading 25 host institutions were all doctoral research institutions, each of which hosted 3,000 or more international students and are located in just $\mathrm{I} 3$ of the 50 US states.

With respect to their personal profile, international students were largely studying business and management, followed by engineering. One major troubling shift in $2004 / 05$ was a 25 percent decline in international student enrollments in mathematics and computer sciences. Other fields of study that showed the largest declines in enrollments included social sciences (I5 percent) and fine and applied arts (I2 percent), with the largest growth in physical and life sciences (II percent) and intensive English language (8 percent). As in the past, the primary source of funding was personal and family funds, with almost two-thirds of international students (62 percent) relying on these funds to support their studies in the United States in 2004/05. The gender ratio has become steadily more balanced since the earlier years of the census, with 44 percent female students in 2004/05 versus 30 percent in the I970s. Unchanged over time are the marital status and visa status of international students, with 85 percent single and 87 percent coming to study on F (student) Visas in 2004/05.

The most significant change has been in total enrollments,

The gender ratio has become steadily more balanced since the earlier years of the census, with 44 percent female students in 2004/05 versus 30 percent in the 1970s.

which has generated a large degree of concern and discussion among US educators, government officials, and business leaders. In I954/55, there were 34,232 international students studying at US colleges and universities. Half a century later, in 2004/05, the number had grown to 565,039. This number represented a decline of I.3 percent from $2003 / 04$, which followed a 2.4 percent decline the previous year, and minimal growth of 0.6 percent in the year prior. These years followed on the heels of two consecutive years of 6.4 percent increases and nearly 30 years of fairly steady and sometimes strong growth. Given the recent reversal, what has been the impetus behind the declines?

\section{Reasons for the Decline}

Much of the decline has been attributed to tightened student visa review procedures implemented after September II, 200I, which included personal interviews for all applicants and other new screening measures. The addition of several hundred consular officers this past year to handle the backlog generated in spring and summer 2002 and 2003 by these new require- 